\title{
Small-sized Fish Assemblages Do not Differ Between a Native and a Recently Established Non-indigenous Macrophyte in a Neotropical Ecosystem
}

\author{
Eduardo Ribeiro Cunha1', Sidinei Magela Thomaz ${ }^{1,2,3}$, Heloísa Beatriz Antoniazi Evangelista², \\ Juliana Carniato ${ }^{3}$, Camila Fernandes Souza ${ }^{3} \&$ Rosemara Fugi11,3,*
}

\author{
'Programa de Pós-graduação em Ecologia de Ambientes Aquáticos Continentais - PEA, \\ Universidade Estadual de Maringá - UEM, Maringá, PR, Brazil
}

${ }^{2}$ Programa de Pós-graduação Em Biologia Comparada - PGB, Universidade Estadual de Maringá, PGB, Maringá, PR, Brazil ${ }^{3}$ Núcleo de Pesquisas em Limnologia e Aquicultura - Nupélia, Universidade Estadual de Maringá - UEM, Maringá, PR, Brazil

\begin{abstract}
Hydrilla verticillata recently invaded a protected area in the Upper Paraná River floodplain. In a rare opportunity, when this non-indigenous species co-occurred with the native Egeria najas in a secondary channel of the river, we assessed its effects on assemblage of small-sized fish. Traps were used to catch fish inside macrophyte patches in periods of low and high water. We assessed fish abundance, biomass, diversity, richness and the community composition (using a DCA). The number of fish species did not differ between plants. Fish abundance and biomass were significantly higher during the low water period but plant species did not affect these attributes. Similarly, fish assemblage composition differed only between seasons. Our results indicate that the oscillations in the water level had a greater effect on the small-sized fish assemblage than the presence of the non-indigenous macrophyte. In addition, $H$. verticillata favors small fish assemblages such as the native does; however, we contend that our conclusions are valid only for habitats scarcely colonized by native plant species. The invasion of other habitats colonized by a high diversity of native species of macrophytes, which are key for small-sized fish, is a matter of concern.
\end{abstract}

Key words: Exotic Species, Hydrilla verticillata, Egeria najas, Paraná River.

\section{Introduction}

Aquatic ecosystems have been colonized by many non-indigenous (NI) species all over the world, leading to concerns in terms of biodiversity and the number of threatened species in these environments (Jenkins 2003). Several species of macrophytes have an extensive ability to disperse and regenerate, which makes them excellent invaders. Their effects, however, can be complex because these plants may change the physical structure of habitats and thus alter the availability of substrate, sites for foraging and refuge for aquatic fauna (Dibble et al. 1996; Dibble \& Pelicice 2010). Some investigations have shown that NI macrophytes do not affect species richness or the abundance of fish and invertebrates (Barrientos \& Allen 2008; Mormul et al. 2010), but others have shown either negative (Colon-Gaud et al. 2004) or positive effects (Strayer et al. 2003; Bickel \& Closs 2008) on aquatic fauna. However, changes in the relative abundance of associated fauna are the mostly reported *Send correspondence to: Rosemara Fugi

Universidade Estadual de Maringá - UEM, Nupélia

Av. Colombo, 5790, CEP 87020-900,

Maringá, PR, Brasil

E-mail: rosemarafugi@gmail.com response to plant invasion, at least for invertebrates (e.g., Strayer et al. 2003; Mormul et al. 2010).

Most studies comparing the effects of NI species either use species that differ in physical structure for fauna or focus on NI macrophytes that colonize multi-specific patches of macrophytes (Barrientos \& Allen 2008). Thus, it is difficult to conclude whether NI macrophytes influence the aquatic fauna by directly changing structural complexity or indirectly by changing native macrophyte communities.

In this study, we investigated the fish assemblages colonizing mono-specific patches of two submerged macrophytes with similar architectures (see details in Cook \& Lüönd 1982) (Figure S1*): the native Egeria najas Planchon and the NI Hydrilla verticillata Royle (egeria and hydrilla hereafter). Hydrilla is most likely native to Asia, but is now spread all over the world (Cook \& Lüönd 1982). This macrophyte was first recorded in the Upper Paraná River floodplain (protected area) in 2005 where it spread quickly. Following six years of invasion, native macrophytes still predominate

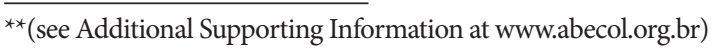


in floodplain lakes, while hydrilla grows prolifically in the main and lateral channels of the river, where colonization by native macrophytes is scarce (Sousa et al. 2009; Sousa 2011). In 2009, one of the Paraná lateral channels was colonized simultaneously by egeria and hydrilla. We took this rare opportunity to investigate whether this NI species changed the fish assemblages in relation to its equivalent egeria. We hypothesized that hydrilla would affect small-sized fish assemblages and we predicted that fish density, diversity and assemblage composition would differ between hydrilla and egeria patches. However, considering that the flood pulse is the main functioning force in the Upper Paraná River, we expected that differences between high and low water periods would surpass the effects of this exotic species.

\section{Study Area}

Samplings were carried out in a secondary channel of the

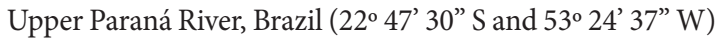
(Figure S2a) located in a river floodplain system, which comprises a diverse mosaic of habitats (e.g. lakes, channels and backwaters). This is the last undammed stretch of the Paraná River remaining in Brazilian territory. For this reason, the area is key for biodiversity conservation and has been transformed into three protected areas. Despite alterations by upstream dam operation, periods of low and high water still exist.

The channel is ca. $2 \mathrm{~km}$ long, shallow ( $<3 \mathrm{~m}$ depth) and 30-90 $\mathrm{m}$ wide, with well-preserved riparian vegetation. Its littoral zone is colonized by free-floating (Eichhornia crassipes), floating (E. azurea) and emergent macrophytes (Polygonum spp.), together with the submerged egeria and hydrilla.

\section{Methods}

Plants and fish were collected on 16-17 April (high water) and 6-7 August 2009 (low water). We used plant biomass as a surrogate of physical structural complexity. In each sample unit, we collected macrophyte biomass in a $0.5 \times 0.5 \mathrm{~m}$ quadrat located in the top $0.3 \mathrm{~m}$ of water column. Plant biomass was dried in an oven at $c a .80{ }^{\circ} \mathrm{C}$ until constant weight. Temperature and dissolved oxygen (YSI digital meters) where recorded in the sub-surface, and depth was also recorded in each macrophyte patch.

We used floating Plexiglas traps (minnow trap type; see details in Dibble \& Pelicice (2010) and Figures S3 and S4) to capture fish. Mono-specific macrophyte patches (three patches per species) were sampled in each period. Each sampling unit consisted of two traps inside patches of egeria and hydrilla (12 traps per sampling). Traps were set up at 11:00 AM and inspected for fish at 3:00, 7:00 PM, 7:00 and 11:00 AM. All captured fish were anesthetized with eugenol, fixed in formalin and identified, counted, measured and weighed in the lab.
Fish density was assessed as individuals 2 traps $^{-1} \mathrm{~d}^{-1}$ and biomass was obtained by their weight $\left(\mathrm{g}^{2} \operatorname{traps}^{-1} \mathrm{~d}^{-1}\right)$. For species richness $(S)$, samples were rarefied with 10,000 randomizations (Gotelli \& Graves 1996). We also calculated the Shannon diversity index $\left(H^{\prime}\right)$ as a measure that integrates species richness and evenness.

Differences in macrophyte biomass, depth, temperature, dissolved oxygen, fish density, biomass, $S$ and $H^{\prime}$ between egeria and hydrilla, and between high and low waters were tested using a two-way ANOVA $(\alpha=0.05)$. For the abiotic variables, we used raw data because all assumptions were reached (homocedasticity and normality) but the fish abundance was log-transformed to make the variance homogeneous.

Differences in fish $S$ of the whole assemblage inhabiting egeria and hydrilla were compared through accumulation curves rescaled by individuals, with 10,000 randomizations (Gotelli \& Colwell 2001). In addition, the accumulation curves allowed assessing whether the asymptote was reached in both species of plants or not.

To test whether the fish assemblage composition differed between egeria and hydrilla, and between high and low water, we summarized our data through a Detrended Correspondence Analysis (DCA; PC-ORD 5.0 statistical software; McCune \& Mefford 1999). The scores of axis 1 were tested for differences through a two-way ANOVA.

\section{Results}

Patches of egeria occurred closer to the shore than patches of hydrilla (Figure S2b); however, both species colonized shallow areas (1.7-2.8 $\mathrm{m}$ in high water; $0.4-1.3 \mathrm{~m}$ in low water). The temperature varied from 26.8 to $29.1{ }^{\circ} \mathrm{C}$ in high water, and from 20.6 to $25.6^{\circ} \mathrm{C}$ in low water; oxygen varied from 7.0 to $13.2 \mathrm{mg} . \mathrm{L}^{-1}$ in high water and from 4.7 to $11.3 \mathrm{mg} . \mathrm{L}^{-1}$ in low water (measurements taken at 11:00 AM and 3:00 PM). The lowest mean biomass was found for hydrilla during low water $\left(84.4 \mathrm{gDW} \mathrm{m}^{-2}\right.$; $\left.\mathrm{SD}=16.0\right)$, and the highest was found for egeria during high water (138.0 $\mathrm{gDW} \mathrm{m}^{-2}$; SD = 32.4) (Figure S5). However, none of these factors differed between plant species or between periods, nor was the interaction effect significant (all $P$ values $>0.05$ ), except for temperature, which only differed between periods $\left(F_{1}=9047.11, P<0.01\right)$. Thus, both macrophytes presented similar habitats in terms of dissolved oxygen, depth, and physical structure (biomass).

We caught 1,767 fish belonging to 18 species: 1,169 individuals (16 species) in egeria and 598 individuals (13 species) in hydrilla. Characidae predominated with 1,701 individuals (10 species). Five species occurred only in egeria (A. commbrae, L. lacustris, S. insculpta, S. maculatus and S. papaterra) and two species only in hydrilla (A. dentatus and $A$. lacustris) (Table 1). However, all species that were exclusive to a particular macrophyte species were captured at low densities ( $<$ three individuals). 
Table 1. Total abundance of fish collected inside of E. najas $(E)$ and $H$. verticillata $(H)$ patches. $H W=$ high water; $L W=l o w$ water; $\mathrm{SL}=$ standard length range $(\mathrm{mm})$.

\begin{tabular}{|c|c|c|c|c|c|}
\hline \multirow[t]{2}{*}{ Fish species } & \multicolumn{2}{|c|}{ HW } & \multicolumn{2}{|c|}{ LW } & \multirow[t]{2}{*}{ SL } \\
\hline & $E$ & $H$ & $E$ & $H$ & \\
\hline \multicolumn{6}{|l|}{ CHARACIFORMES } \\
\hline \multicolumn{6}{|l|}{ ACESTRORHYNCHIDAE } \\
\hline Acestrorhynchus lacustris (Lütken, 1875)* & - & 1 & - & - & 79.3 \\
\hline \multicolumn{6}{|l|}{ ANOSTOMIDAE } \\
\hline Leporinus lacustris Campos, $1945^{*}$ & 1 & - & - & - & 31.8 \\
\hline \multicolumn{6}{|l|}{ CHARACIDAE } \\
\hline Astyanax altiparanae Garutti \& Britski, 2000 & 40 & 44 & 6 & 12 & $20.2-46.1$ \\
\hline Aphyocharax anisitsi Eigenmann \& Kennedy, 1903 & 1 & 3 & - & 1 & $28.2-30.3$ \\
\hline Aphyocharax edentatus Eigenmann \& Kennedy, 1903 & - & 1 & - & 2 & $23.5-33.7$ \\
\hline Bryconamericus exodon Eigenmann, 1907 & - & - & 1 & 1 & $33.0-36.5$ \\
\hline Hyphessobrycon eques (Steindachner, 1882) & 1 & - & 56 & 15 & 15.4-23.9 \\
\hline Hemigrammus marginatus Ellis, 1911 & 25 & 82 & 387 & 265 & $9.0-37.5$ \\
\hline Moenkhausia forestii Benine, Mariguela \& Oliveira, 2009 & 2 & - & 6 & 8 & $22.0-37.3$ \\
\hline Psellogrammus kennedyi (Eigenmann, 1903) & - & - & 9 & 2 & $29.2-41.4$ \\
\hline Serrasalmus maculatus Kner, $1858^{*}$ & 2 & - & 1 & - & $27.3-42.6$ \\
\hline Serrapinnus notomelas (Eigenmann, 1915) & 8 & - & 590 & 130 & $12.1-33.6$ \\
\hline \multicolumn{6}{|l|}{ CURIMATIDAE } \\
\hline Steindachnerina brevipinna (Eigenmann \& Eigenmann, 1889* & - & - & 6 & 3 & $25.1-37.9$ \\
\hline Steindachnerina insculpta (Fernández-Yépez, 1948)* & - & - & 2 & - & $40.4-48.3$ \\
\hline \multicolumn{6}{|l|}{ CYPRINODONTIFORMES } \\
\hline \multicolumn{6}{|l|}{ POECILIIDAE } \\
\hline Pamphorichthys sp. & 4 & 1 & 8 & 26 & $10.3-24.4$ \\
\hline \multicolumn{6}{|l|}{ PERCIFORMES } \\
\hline \multicolumn{6}{|l|}{ CICHLIDAE } \\
\hline Apistogramma commbrae (Regan, 1906) & - & - & 3 & - & $20.4-29.7$ \\
\hline Laetacara araguaiae Ottoni \& Costa, 2009 & 3 & - & 6 & 1 & $22.6-41.2$ \\
\hline Satanoperca papaterra $($ Heckel, 1840)* & - & - & 1 & - & 44.5 \\
\hline Total & 87 & 132 & 1082 & 466 & \\
\hline
\end{tabular}

${ }^{\star}$ Juveniles of medium-sized species according to Suzuki et al. (2004).

Fish sizes varied from 9.0 to $48.3 \mathrm{~mm}$ with the exception of one individual measuring $79.3 \mathrm{~mm}$ (Table 1). The majority of individuals were adults of small-sized, non-migratory species, although we also caught juveniles of medium-sized species (Table 1). There were no juvenile individuals of large migratory fish species.

The fish density and biomass were similar between egeria and hydrilla ( $P$ values $>0.05)$, but fish density and biomass increased significantly in both species of macrophytes during low water (density: $F_{1}=13.73, P<0.01$; biomass: $\left.F_{1}=12.86, P<0.01\right)($ Figures 1a, b); the interaction effects were not significant $(P>0.05)$. For rarefied $S$, there was a significant interaction between macrophyte species and season $\left(F_{1}=7.37, P<0.05\right)$. $S$ was higher in egeria during the high water and in hydrilla during the low water (Figure 1c). The $H^{\prime}$ index did not differ between macrophytes and periods, nor were the interaction effects significant (all $P$ values $>0.05)$.

The accumulation curves show that fish $S$ of the whole assemblage did not differ between macrophyte species when accounting for abundance, as indicated by the overlap between the curves (Figure 2). In addition, richness did not reach an asymptote for any species of macrophytes, indicating that for egeria as well as hydrilla, more species could be caught with increased sampling effort.

The first axis of the DCA (Figure 3) was the only one retained for analysis and explained $27 \%$ of the total data variance. The scores of axis 1 differed significantly between periods $\left(F_{1}=20.06 ; P<0.01\right)$, but not between macrophyte species $\left(F_{1}=0.67 ; P>0.05\right)$; the interaction effect was also not significant $\left(F_{1}=2.90 ; P>0.05\right)$.

\section{Discussion}

Hydrilla has invaded freshwaters on almost all continents (Cook \& Lüönd 1982) and it has a high growth rate compared to native macrophytes (Bianchini Junior et al. 2010). Investigations on its impact on aquatic assemblages have obtained different and sometimes opposing results (e.g., Rybicki \& Landwehr 2007; Barrientos \& Allen 2008; Bickel \& Closs 2008; Theel et al. 2008; Mormul et al. 2010); this 

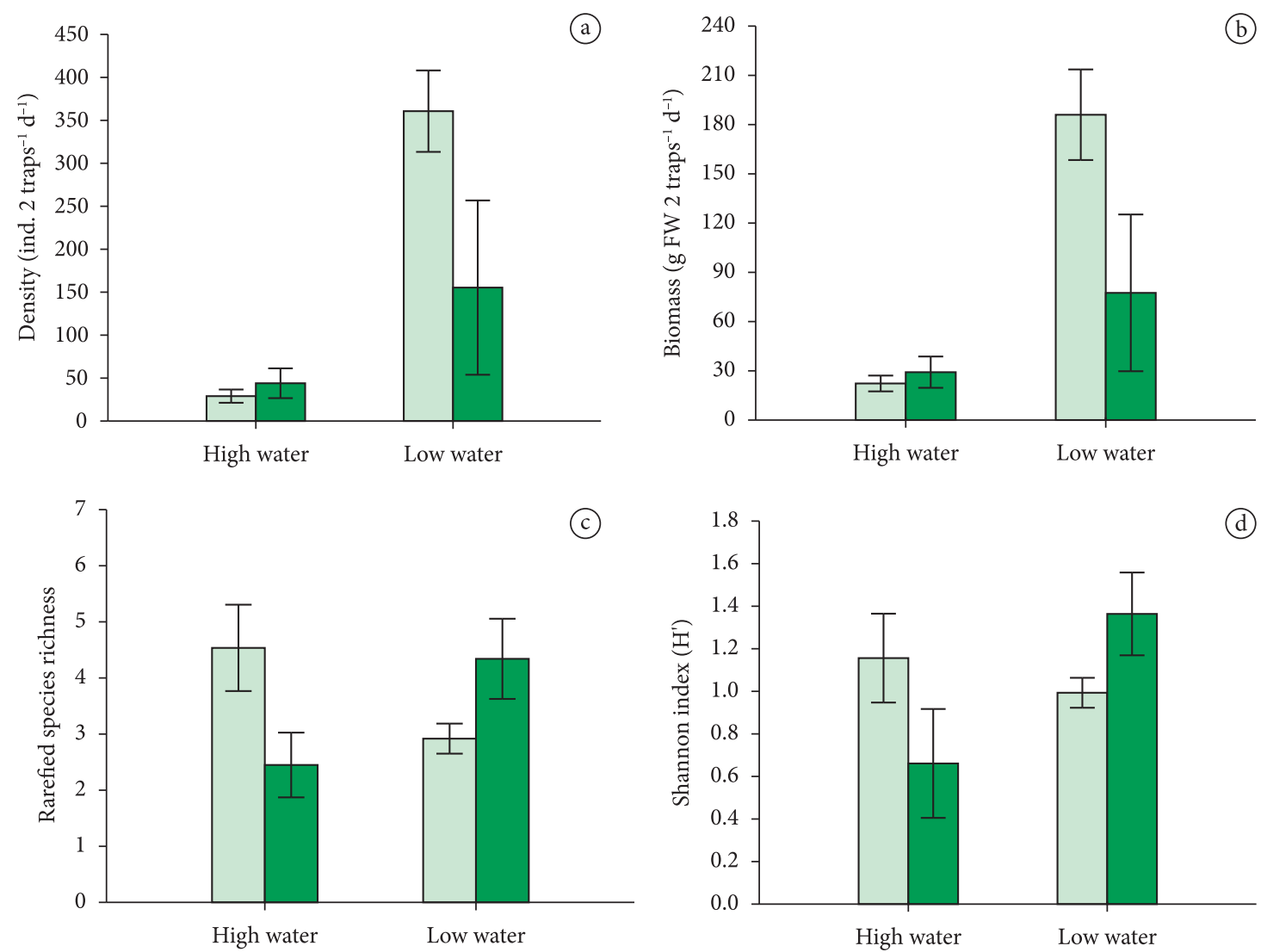

Figure 1. Mean values ( \pm SE) of the a) fish density; b) fish biomass; c) rarefied richness; and d) $H^{\prime}$ of the fish assemblages associated with E. najas (light green bars) and H. verticillata (dark green bars).

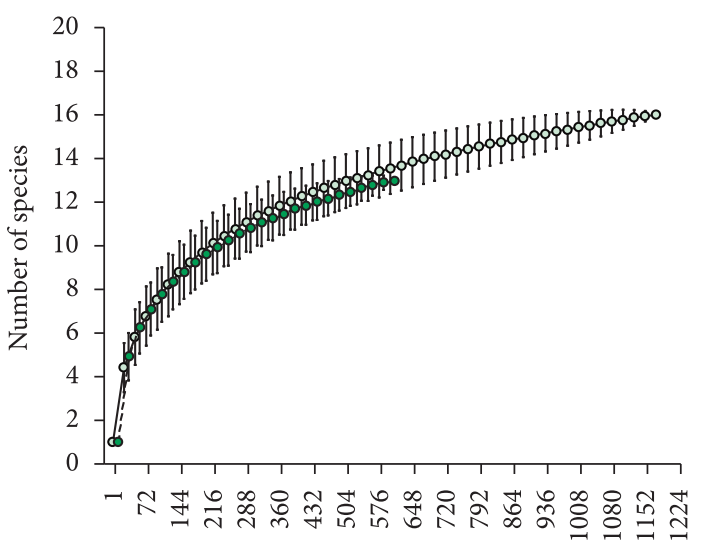

Fish abundance

Figure 2. Fish species accumulation curves in patches of E. najas (light green circles) and $H$. verticillata (dark green circles). Whiskers represent standard deviation.

makes general conclusions difficult. Our results showed that none of the fish community attributes (density, biomass, rarefied $S, H^{\prime}$, total $S$ and assemblage composition) differed significantly between egeria and hydrilla patches. The lack of effects of hydrilla on small-sized fish assemblages may be explained by at least two non-exclusive factors. First, both

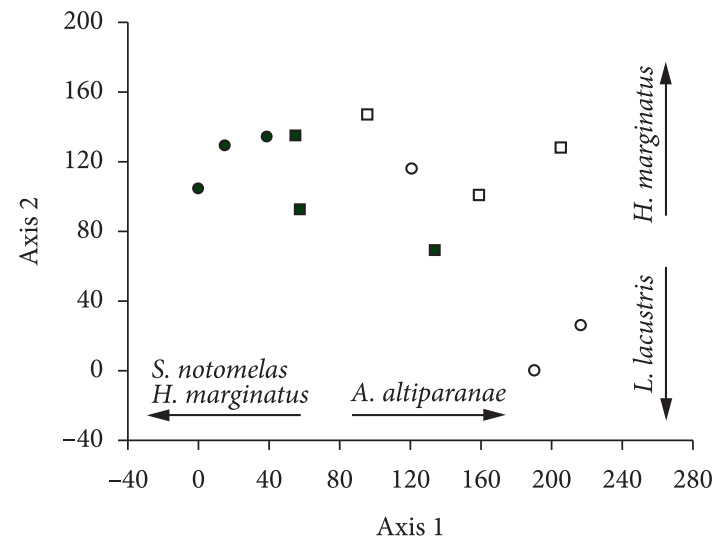

Figure 3. Ordination of fish assemblages (using the two first DCA axes) by species of macrophyte and water period. E. najas: circles; $H$. verticillata: squares; high water: full symbols; low water: empty symbols. Arrows indicate the species most positively and negatively associated with axes one and two.

species of macrophytes have a similar architecture (Cook \& Lüönd 1982; Figure S1) and do not differ in their physical structural complexity (as indicated by similar biomasses). In fact, plant architecture has been considered among the most important variables to explain patterns of diversity and composition of aquatic communities (Dibble et al. 
1996; Petry et al. 2010; Dibble \& Pelicice 2010). Second, both egeria and hydrilla are canopy-forming species (Cook \& Lüönd 1982), which means that they occupy the same strata in the water column. As a consequence of these two factors, it seems that small-sized fish perceive the habitat provided by both plant species in a similar way.

The flood pulse had a greater role than the presence of hydrilla on the structure of the small-sized fish assemblages, as was indicated by significant differences in fish biomass, density and composition (evidenced by DCA axis 1) between periods. Water level fluctuations are considered the most important factor influencing communities in river-floodplain systems (Agostinho et al. 2004) and affect fish by changing the abiotic medium, food availability (Hahn et al. 2004), reproduction, growth, mortality and competitive relationships (Agostinho et al. 2001). In addition, floods increase habitat availability, and during high waters, fish explore flooded areas in search of food and refuge (Gomes \& Agostinho 1997; Agostinho et al. 2004; Dibble \& Pelicice 2010). In addition, the simple effect of increase in water volume reduces fish density during high water (Agostinho et al. 2001).

The significant interaction between macrophyte species and periods for rarefied fish $S$ shows that changes in the number of fish species in both species of macrophytes depend on water level. Such results indicate that the flood pulse is also important for maintaining diversity of the small-sized fish assemblage, whose individuals may change between plants in different periods. Consequently, it seems that water level fluctuations also minimize the potential effects of hydrilla in the Upper Paraná River habitats.

Based on the similarities of the fish assemblages colonizing the native egeria and the NI hydrilla, we could not demonstrate any direct impact of this NI species on fish assemblages. Hydrilla primarily colonizes the lotic habitats of the Paraná River, such as its main and lateral channels. These habitats are rarely colonized by native species, and hydrilla is rarely recorded in other habitats such as floodplain lakes (Sousa et al. 2009; Sousa 2011). If hydrilla continues to exhibit this pattern of distribution, it will add physical structure to previously scarcely colonized habitats, facilitating fish colonization such as the native egeria would do. However, this conclusion should be taken with caution, as we compared mono-specific patches of hydrilla with mono-specific patches of egeria, two extremely similar species in terms of biomass and habitat structuring. The competitive ability of hydrilla under other abiotic conditions prevalent in floodplain lakes is unknown. Some of these lakes are colonized by multi-specific patches of macrophytes, whose structure is key to maintaining small-sized fish diversity (Dibble \& Pelicice 2010). Although hydrilla has not currently colonized the Upper Paraná River floodplain lakes, it is a recent invader and can colonize other sites following a time lag. If this occurs, changes in fish communities in response to elimination of native macrophyte species (e.g., Dibble \&
Pelicice 2010) and to alterations in water physico-chemistry promoted by hydrilla are expected (Kovalenko et al. 2010). Thus, although our results suggest that hydrilla may benefit fish assemblages in the Paraná River channel, its effects on lentic habitats is a matter of concern.

\section{Acknowledgements}

We thank AA Agostinho (Universidade Estadual de Maringá), LM Bini (Universidade Federal de Goiás) and an anonymous reviewer who greatly improved this manuscript, and RP Ota for fish identification. JC Oliveira, CF de Souza, ER Cunha and HBA Evangelista acknowledge the Brazilian Council of Research (CNPq) and CAPES for providing grants. SM Thomaz is especially thankful to the CNPq for continuous funding through a Research Productivity Grant, which provided resources to carry out this investigation.

\section{References}

Agostinho AA et al., 2004. Flood regime, dam regulation and fish in Upper Paraná River: effects on assemblage attributes, reproduction and recruitment. Reviews of fish biology and Fisheries, 14:11-19. http://dx.doi.org/10.1007/ s11160-004-3551-y

Agostinho AA, Gomes LC \& Zalewski M, 2001. The importance of floodplains for the dynamics of fish communities of the Upper River Paraná. International Journal of Ecohydrology \& Hydrobiology, 1:209-217.

Barrientos CA \& Allen MS, 2008. Fish abundance and community composition in native and non-native plants following hydrilla colonisation at Lake Izabal, Guatemala. Fisheries Management and Ecology, 15:99-106. http://dx.doi. org/10.1111/j.1365-2400.2007.00588.x

Bianchini Junior I et al., 2010. Growth of Hydrilla verticillata (L.f.) Royle under controlled conditions. Hydrobiologia, 644:301-312. http://dx.doi.org/10.1007/s10750-010-0191-1

Bickel TO \& Closs GP, 2008. Fish distribution and diet in relation to the invasive macrophyte Lagarosiphon major in the littoral zone of Lake Dunstan, New Zealand. Ecology of Freshwater Fish, 17:10-19. http://dx.doi. org/10.1111/j.1600-0633.2007.00249.x

Colon-Gaud JC, Kelso WE \& Rutherford DA, 2004. Spatial distribution of macroinvertebrates inhabiting hydrilla and coontais beds in the Atchafalaya Basin, Louisiana. Journal of Aquatic Plant Management, 42:85-91.

Cook CDK \& Lüönd R, 1982. A revision of the genus Hydrilla (Hydrocharitaceae). Aquatic Botany, 13:485-504. http:// dx.doi.org/10.1016/0304-3770(82)90074-2

Dibble ED, Killgore KJ \& Harrel SL, 1996. Assessment of fish plant interactions. American Fisheries Society, 16:357-372.

Dibble ED \& Pelicice FM, 2010. Influence of aquatic plantspecific habitat on an assemblage of small Neotropical floodplain fishes. Ecology of Freshwater Fish, 19:381-389. http://dx.doi.org/10.1111/j.1600-0633.2010.00420.x

Gomes LC \& Agostinho AA, 1997. Influence of the flooding regime on the nutricional state and juvenile recruitment of 
the curimba, Prochilodus scrofa, Steidachner, in upper Paraná River, Brazil. Fisheries Management and Ecology, 4:263-274. http://dx.doi.org/10.1046/j.1365-2400.1997.00119.x

Gotelli NJ \& Graves GR, 1996. Null Models in Ecology. Washington: Smithsonian Institution Press.

Gotelli NJ \& Colwell RK, 2001. Quantifying biodiversity: procedures and pitfalls in the measurement and comparisons of species richness. Ecology letters, 4:379-391. http://dx.doi. org/10.1046/j.1461-0248.2001.00230.x

Hahn NS, Fugi R \& Andrian IF, 2004. Trophic Ecology of the fish assemblage. In: Thomaz SM et al., (eds.).The upper Paraná River and its floodplain: physical aspects, ecology and conservation. Leiden: Backhuys Publishers. p. 247-269.

Jenkins M, 2003. Prospects for Biodiversity. Science, 302:1175-1177. http://dx.doi.org/10.1126/science.1088666

Kovalenko KE et al., 2010. Direct and indirect effects of an introduced piscivore, Cichla kelberi and their modification by aquatic plants. Hydrobiologia, 638:245-253. http://dx.doi. org/10.1007/s10750-009-0049-6

McCune B \& Mefford MJ, 1999. PC-ORD Multivariate Analysis of Ecological Data. Version 5.0. Available from: <http:// home.centurytel.net/ mjm/pcordwin.htm $>$.

Mormul RP et al., 2010. Ostracod (Crustacea) colonization of a native and a non-native macrophyte species of Hydrocharitaceae in the Upper Paraná floodplain (Brazil): an experimental evaluation. Hydrobiologia, 644:185-193. http://dx.doi.org/10.1007/s10750-010-0112-3

Petry AC et al., 2010. The role of the predatory trahira (Pisces: Erythrinidae) in structuring fish assemblages in lakes of a
Neotropical floodplain. Hydrobiologia, 651:115-126. http:// dx.doi.org/10.1007/s10750-010-0281-0

Rybicki NB \& Landwehr JM, 2007. Long-term changes in abundance and diversity of macrophyte and waterfowl populations in an estuary with exotic macrophytes and improving water quality. Limnology and Oceanography, 52:1195-1207. http://dx.doi.org/10.4319/lo.2007.52.3.1195

Sousa WTZ et al., 2009. Environmental predictors of the occurrence of exotic Hydrilla verticillata (L.f.) Royle and native Egeria najas Planch. in a sub-tropical river floodplain: the Upper River Paraná, Brazil. Hydrobiologia, 632:65-78. http://dx.doi.org/10.1007/s10750-009-9828-3

Sousa WTZ, 2011. Hydrilla verticillata (Hydrocharitaceae), a recent invader threatening Brazil's freshwater environments: a review of the extent of the problem. Hydrobiologia, 669:1-20. http://dx.doi.org/10.1007/s10750-011-0696-2

Strayer DL et al., 2003. Invertebrate Communities associated with a native (Vallisneria americana) and an alien (Trapa natans) macrophyte in a large river. Freshwater Biology, 48:1938-1949. http://dx.doi.org/10.1046/j.1365-2427.2003.01142.x

Suzuki HI et al., 2004. Reproductive ecology of the fish assemblages. In: Thomaz SM et al., (eds.). The upper Paraná River and its floodplain: physical aspects, ecology and conservation. Leiden: Backhuys Publishers. p. 271-291.

Theel HJ, Dibble ED \& Madsen JD, 2008. Differential influence of a monotypic and diverse native aquatic plant bed on a macroinvertebrate assemblage: an experimental implication of exotic plant induced habitat. Hydrobiologia, 600:77-87. http://dx.doi.org/10.1007/s10750-007-9177-z

Received: May 2011

First Decision: May 2011

Accepted: May 2011 